\title{
السمات المنشودة في الحطاب التربوي الإسلامي
}

\section{دكتور /أحمد المهدي عبد الحليم*}

\section{تمهيد: الخطاب التربوي الإسلامي في مواجهة التحديات}

تنصب هذه الدراسة على الخصائص التي ينبغي توفرها في الخطاب التربوي الإسلامي؛ فهي ليست محاولة لتحليل الخطاب التربوي الراهن، وإنما هي رؤية لما يجب الالتزام به ـ في رأي الكاتب ـ في الخطاب التربوي المستقبلي. وأعتقد أن الحاجة باتت ملحة لبذل مزيد من العناية، وكثير من الجهد الهادف لاتخاذ التربية أداة فعالة لتوعية الناس في العالمين: العربي والإسلامي بأخطار التحديات التي تواجهرم في جوانب حياقم المختلفة: السياسية والاقتصادية والاجتماعية والعلمية والثقافية والتقنية.

ولست في حاجة إلى تعداد هذه التحديات؛ لأفا توشك أن تكون معروفة غير منكورة، ظاهرة غير مستورة، لعامة الناس وخاصتهم.

وقد يكفي في هذا المقام أن أشير إلى تحديات طال عليها الزمن، وسوغت تصنيف البلاد العربية والإسلامية ضمن الدول المتخلفة أو الساعية إلى النمو، وبجاهة مظاهر التخلف الاقتصادي والسياسي والعلمي، الذي أدى إلى بطء التنمية البشرية في هذه البلاد، بالمعنى الواسع لمفهوم التنمية، الذي يشمل: تحسين الأوضاع الاقتصادية بحيث تكفل سد الحاجات الأساسية لمواطني هذه الدول من الغذاء والكساء والمسكن والدواء، دون اعتماد كبير على ألى الاستيراد و /أو الاقتراض من دول أجنبية؛ وتعظيم معدل النمو السنوي للإنتاج العام في كل منها، وتخفيض معدل التضخم بما يتيح للناس فرص عمل منتج؛ يحقق من خلالها كل فرد ذاته، ويسهم في تنمية مجتمعه؛ على أن يواكب ذلك جهد مقصود لرفع المستوى المعرفي للمواطنين؛ مقيساً بإجادة القراءة والكتابة، وزيادة عدد سنوات الدراسة التي تنتظم فيها جماهير المواطنين في مؤسسات التعليم النظامي التي يناط بها تنمية المستوى الفكري والمعريف لدى جماهير 
ويتضمن المفهوم الواسع للتنمية ـ أيضاً . زيادة الفرص التي تستنفر الكوامن الثقافية لدى الناس، وتظهرها في صور مختلفة للإبداع الجمالي والفني، وتوسيع فرص التواصل بين أبناء الثقافة العربية الإسلامية في شتى الأقطار، ووصلهم بمنجزات الثقافات الأخرى؛ على نحو يصون الثقافة العربية الإسلامية في ثوابتها، ويجدد ـ في الوقت ذاته ـ. متغيراتا؛ بما يهيئ لمواطني هذه البلاد الانتفاع بالمنجزات العلمية والثقافية والتقنية المعاصرة، وبما يكفل إسهامهم في

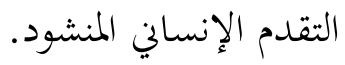

تلك هي التحديات التليدة التي واجهت ـ ولا تزال تواجه ـ الأمة العربية والإسلامية. وقد أُضيفت إليها تحديات استجدت بعد أحداث يوم الثلاثاء 11 سبتمبر 2001م في نيويورك وواشنط، تمخضت عما يشبه "إعلان حرب" على الإسلام والمسلمين، من جانب دول الغرب، بقيادة الولايات المتحدة الأمريكية، ووصْفَ الإسلام بأنه"العدو الأخضر" الذي يجب الحذر منه و تأديبه. ولعل أخطر ما في هذا التحدي الجديد سعي أمريكا الدائب وبوسائل شتى، إلى محاولة تشكيل عقول المسلمين على النحو الذي يخدم مصالحها، وذلك بدعوقا الصريحة والمعلنة لبعض الدول الإسلامية بضرورة مراجعة منهج التعليم فيها، بحيث يتم القضاء على ما أسموه "الإسلام الراديكالي" وتنقية مناهج

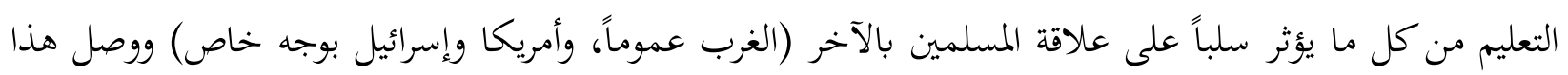
السعي إلى أن أحد كتاهم (توماس فريدمان) كتب إلى مسئول في دولة إسلامية بضرورة تحديد عدد الساعات التي تخصص لتعليم مواد الثقافة الإسلامية في المدارس والمعاهد الدينية، وإلى تمديد الدول الإسلامية التي لا تغّير مناهج التعليم على النحو الذي تريده أمريكا باعتبارها "مارقة" و"معادية" لأمريكا؛ على نحو ما كان عليه الاتحاد السوفيتي في ظل الشيوعية (العدو الأحمر).

وأعتقد أن هذا التحدي الجديد يمثل أحد الدواعي الملحة للنظر فيما ينبغي أن يكون عليه الخطاب التربوي الإسلامي، على نخو ينفي صور التشويه والتضليل والافتراء التي تنسبها الحملات المعادية للإسلام "الدين" ولإسلام "الحضارة"، ويوضّح في الوقت ذاته التجليات الحقيقية للإسلام: عقيدة وشريعة، ونمط حياة؛ حتى يتضح للمفكرين في الساحتين - الإسلامية والغربية - الحق من الباطل.

أولاً: ضبط المصطلحات

1 
تستند هذه الدراسة إلى تحديد معين لمفاهيم ثلاثة تضمنها عنوان الدراسة: الخطاب، والتربية، والإسلام. وأوجز

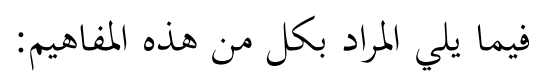

1

"الخطاب" لغة على وزن فعال من خاطب، ومصدره خطاب، ومخاطبة على وزن مفاعلة، ومعناه الكلام والمحادثة، ومراجعة الكلام والمشاورة فيه. "وفصل الخطاب" هو ما ينفصل به الأمر من الخطاب بالبينة أو اليمين في شؤون القضاء أو الحكم الفقهي، وقيل أن فصل الخطاب معناه الفصل بين الحق والباطل، وأن يميز فيه بين الحكم وضده. وقيل -أيضاً " "إنه خطاب لا يكون فيه اختصار مخل، ولا إسهاب ممل."2"

ويستعمل لفظ "الخطاب" اصطلاحاً بمعاني شتى، تختلف تبعاً لطبيعة الموضوع الذي ينصب عليه الخطاب، وتبعاً للأغراض التي يتوخى تحقيقها منه؛ ففي التشريع والقضاء تعني "بلاغة الخطاب" أن يؤسس على البرهان الاستدلالي، على النحو الذي يحدده المنطق، وفلسفة التشريع، والأيديلوجية المتبناة في صياغة التشريعات، وفي أحكام القضاء. ومعنى هذا أن الخطاب يتجاوز الشكلانية اللغوية ويمتد إلى وسائل الإقناع، ونوعية البرهان، وأدوات الأسلوب البياني.

وفي علم اللغويات يرى عالم اللغة فردينان دى سوسيير (سويسري الجنسية، فرنسي اللغة) أن الخطاب مصطلح

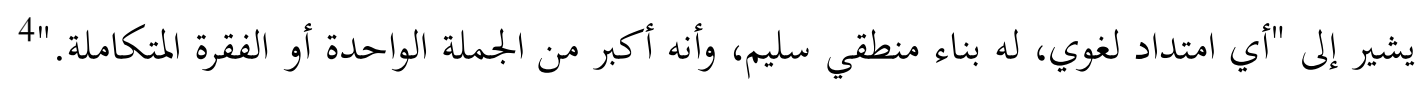
وفي علوم الأدب استحدث علم جديد عرف بعلم "النص" وفيه تدرس الأبنية الخاصة بنمط النص، وبالوظائف الجمالية والبرهانية التي تتجلى في الأقوال والنصوص الأدبية في أنماطها المتعددة وفي سياقاتا المختلفة، ويهتم في ذلك ببيان العلاقة بين بنية النص وعناصر الموقف التواصلي مرتبطة بسياقه، وهذا هو ما عرف في البلاغة العربية القديمة بمراعاة "مقتضى الحال" وتكملها المقولة التي ولدت عن مقتضى الحال، وصيغت في أنه: "لكل مقام مقال." ابن منظور، لسان العرب. بيروت: دار صادر، 2000م ج: 5، ص98. وبجمع اللغة العربية، المعجم البسيط، القاهرة: جممع اللغة العربية،

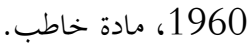
3 4 
ويذكر صلاح فضل أن مدلول هاتين المقولتين قد سبق إليه شيشرون Ciceron في قوله:

"إن الرجل البليغ يجب أن يقدم قبل كل شيء البراهين على حكمته، ويتكيف مع مختلف الظروف

والشخصيات، وأعتقد بالفعل بأنه يجب ألا يتكلم دائماً بنفس الطريقة أمام الجميع، ولا ضد كل شيء، ولا لصالح

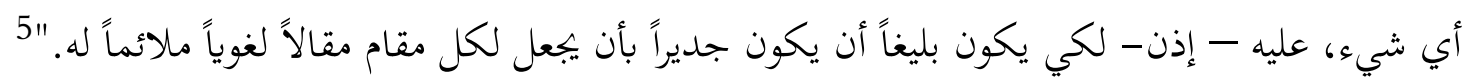

وفي علم اللغة الاجتماعي تجرى محاولات لدراسة الخطاب، تطبق فيها تقنية "تحليل الخطاب" التي عرفت قبل هذا بتقنية "تحليل المضمون" وتمثل محاولة لتحليل النصوص، وإحلال مفرداتا وسياقاتا، في صنوف، تعد مسبقاً أو تشتق من بنية النصوص، وحساب تكرارات المفردات والأسيقة، ومعالجتها إحصائياً، بصورة تكشف -كمياً وكيفياًعن التوجهات الرئيسية في الخطاب.

والجهود التي تبذل في تحليل الخطاب Discourse analysis مدفوعة برغبة من يقومون بها بدراسة الخطاب دراسة علمية تتسم بالصرامة والدقة، وشدة الانضباط. وبرغم تقديري لمثل هذه الجهود فإن لي عليها اعتراضات كثيرة، لن أشغل القارئ بتفاصيلها، وإنما سوف أكتفي بالقول:

إن مثل هذا التحليل معنيٌ - عادة - بخطاب محدد الأطر، يتم في زمان معين، وفي مواقع محددة ومحدودة، لأناس أو هيئات ذات أثر في موضوع الخطاب. وهذه حالة يصعب تطبيقها على خطاب وصف بأنه منشود بمعنى مطلوب في مجال معقد، وفي نظام معرفي يوصف بأنه علم أداء أو ممارسة؛ ترفده وتتداخل فيه أنظمة معرفية شتى . إن مناط التركيز في الدراسة الحالية لا ينصب على تحليل الخطاب، وإنما يقع على" إنشاء "الخطاب أو تكوينه، واقتراح بعض الضوابط العامة والمعايير الكلية؛ التي يمكن الاهتداء بها في الخطاب التربوي الإسلامي في المستقبل.

إن " تحليل الخطاب" على النحو الذي يتم به في العلوم الاجتماعية، والتربية في قلب هذه العلوم، يولي أهمية قصوى، للقطب المنشئ للخطاب. ولمضمون الخطاب، وأبنيته الفردية والسياقية، ولمعاني 
والأفكار والقيم التي ضمنت في الخطاب، ويفترض -خطأ- بأن المعاني والأفكار والقيم التي ضمنت في الخطاب سوف تنتقل -على النحو الذي أراده منشئ الخطاب- إلى عقول من يتلقون هذا الخطاب. ومن شائنات هذا الافتراض في المنهج "التحليلي- الامبيريقي" في البحث التربوي حرصُ الباحثين على جمع المعلومات اللفظية عن المفحوصين ومنهم في المواقف المختلفة، ومسارعتهم إلى تفسير المعلومات وكأها "عملات" ذات وزن موضوعي مادي، لا يختلف في تقديره طرفا التواصل .

وفي عبارة أخرى أقول: إن الخطاب اللغوي كلام، يؤدي شفوياً، أو يسجل كتابياً وإلكترونياً، وهذا الكلام بذاته، وفي ذاته ليس حقائق في الواقع المعيش، وإنما هو "مثثلات" لمعاني وأفكار وأحاسيس، تعكس الواقع الفيزيقي والاجتماعي والثقافي في مرآة عقل منشئ الخطاب، ومرايا العقول كمرايا العيون - محدبة ومقعرة ومستوية. لا تنقل، الواقع بكل تفاصيله وأبعاده؛ وإنما تستخدم اللغة وسيطاً، لنقل ما انعكس من الواقع، فن بنية سطحية للغة (ألفاظ وتراكيب وجمل وفقرات) وهذا ما يتم تحليله في الخطاب.

وليست البنية السطحية إلا أردية لفظية ينسجها منشئ اللغة في نسق معين، لمعان وأفكار ومعتقدات وصفها الجاحظ بأها "المعاني القائمة في صدور العباد، المتصورة في أذهاهم، والمتجلجة في نفوسهم، والمتصلة بخواطرهم، والحادثة عن فكرهم مستورة خفية، ومحوبة مكنونة، وموجودة في معاني معدومة."6

والألفاظ والجمل والعبارات والفقرات لا تحمل في ذاتا معنيً، وإنما هي مادة خامدة، في بطون الكتب أو المطبوعات أو التسجيلات الصوتية، وتظل هكذا، حتى تتاح لقارئ أو مستمع، فتبعث فيها الحياة، من خلال ما تثيره في نفس المتلقي من معان وأفكار ومعتقدات، بتجئ دائماً غخضبة بالخلفية المعرفية للمتلقي: Metacognition خبراته ومعارفه وأسلوبه في التعرف، وابتاهاته وميوله في الفكر وفي العمل. وبهذا فان المتلقي ينشئ بنية جديدة لما يقرأ أو يسمع، وقد تنحرف هذه البنية كثيراً أو قليلاً عما أراد منشئ الخطاب اللغوي أن ينقله إلى عقول من يتلقون الخطاب، ولكنها -بالتأكيد- ليست مطابقة تمام التطابق للمعني الذي قام بنسجه منشئ اللغة في خطابه. وأخلص من كل ما ذكرت إلى تأكيد أن منشئ اللغة ينسج لغة لمعان اختلجت في نفسه، وأن متلقي الخطاب اللغوي ينسج

$$
6
$$


بنية عميقة من المعاني والأفكار لما يسمع أو يقرأ، وحين يدعى للتعبير عن هذه المعاني ينتج لغة "ثوباً" يختلف نسجه بدرجات مختلفة عما انتج منشئ اللغة.

والدراسة الحالية معنية بتكوين الخطاب التربوي في ضوء ضوابط وقيود، يستلهمها كاتب الدراسة من طبيعة

الخطاب ومن ثوابت الثقافة الإسلامية، ومن مقتضيات التطور المعريف في مجال التربية بوصفها "مهنة للتعلم"، وأنه يككن التحدث عن أوصاف المفاهيم والممارسات الكلية التي يتم تداولها في هذه المهنة.

وأفى القول في مفهوم "الخطاب" بتأكيد أن منشئ الخطاب التربوي في أي مستوي من مستوياته يجب أن يراعي في خطابه مقتضى حال المخاطبين العقلي والاجتماعي والعلمي والثقافي والمهني، وأن يلائم خطابه لمستوي دافعيتهم واهتماماتم بمضامين الخطاب.

\section{2.}

نستعمل مصطلح التربية في هذه الدراسة ونريد به "التربية النظامية المقصودة" مثثلة في السياسات والتنظيمات والأنشطة التي تمارسها مؤسسات محدودة في المجتمع (المدارس والجامعات) وهي مؤسسات في كل مجتمع ذات بنيات وأهداف خاصة، غايتها نقل التراث الثقافي للأمة، ونقده وبتحيده بصورة تلائم مقتضيات السياق الزمكانى الذي يكتنف هذه الأمة؛ وبعبارة أخرى أقول: إن غاية التربية المقصودة هي أن يكتسب الجيل الناشئ -أفراداً ومجتمعاًأفكاراً ومعلومات وقيماً وسمات للشخصية، تجعله أكثر قدره على تحقيق ذاته، وأكثر إسهاما في تحقيق أهداف مجتمعه، وإنجاز طموحاته.

وفهم التربية على هذا النحو يعني أن التربية المقصودة في أي بجتمع ليست نظاماً مكتفياً بذاته، وإنما هي نظام ذو علاقة وثيقة بالأوضاع السياسية والاقتصادية والاجتماعية والثقافية في المجتمع الذي تخدمه التربية.

والتربية على هذا الوجه ليست نظاماً معرفياً ذا بنية منضبطة على النحو الذي نجده في الفيزياء أو الرياضيات أو الجغرافيا، وإنما هي علم بمعنى آخر، إنا "علم أداء"، أو علم ممارسة Praxiology كالزراعة والطب؛ أي إنها علم يشتق معارفه ومبادئه وقواعده من علوم أخرى كالفيزياء والبيولوجيا والفلسفة وعلوم اللغة، والاجتماع، وعلوم النفس، وعلوم التواصل، ثم تختبر هذه المعارف النظرية في المجال العملي في مؤسسات التعليم؛ بالممارسة البصيرة، التي يمكن أن 
تضيف إلى المعارف النظرية؛ لتكون أكثر صلاحية للتطبيق العملي. فالتربية -إذن- علم يلتئم فيه الفكر النظري مع التطبيق العملي، وانفكاك أحدهما عن الآخر يحيل الفكر النظري إلى "هرطقة" ويبعل التطبيق العملي عملاً عشوائياً؛ يقوم على المحاولة والحطأ، وكلاهما: الهرطقة والعشوائية مما لم يعد محتملاً في المجتمعات المعاصرة بعامة، وفي المجتمعات

بقي أن أضيف إلى ما قدمت أن نظام التعليم المدرسي schooling يككن وصفه بأنه"نسق" ثقافي إيكولوجي؛ بمعني أنه منظومة معقدة في مكوناتما وفي وظائفها وفي عملياها، فهو إذن "نظام" قابل للفهم والتحليل والتشخيص والتطوير، ولكنه نظام "ثقافي" أي أنه ليس مماثلاً لنظام المصانع والمؤسسات الاقتصادية والتجارية ومؤسسات الخدمات العامة، وإنما هو نظام يضم مجموعات من البشر (الطلاب والمعلمون) لديهم مجموعة من المعتقدات والقيم والمثل والاتحاهات والاهتمامات والمعارف، تدفعهم إلى النهوض بأعمال بذاتما، والعزوف عن أعمال أخرى، وبتعلهم يتقبلون بعض الأفكار ويتحمسون لها، وفي -الوقت ذاته- يرفضون أفكاراً أخرى ويقاوموها. وتطوير

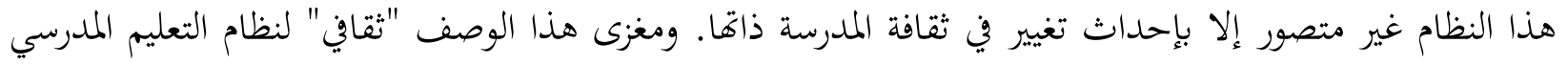
هو أن الفرض والإملاء والهيمنة والقسر وسائل غير مجدية في تطوير هذا النظام.

ووصف النظام بأنه "ايكولوجي" يعني أن مؤسساته (المدارس) تحل في بيئة طبيعية، وتكتنفها بيئة اجتماعية، وهذه البيئة بشقيها تؤثر في التوقعات المنتظرة من المدرسة. كما تؤثر في أداء العاملين فيها. وأستخلص مما قدمت حول مفهوم التربية أن الخطاب التربوي المنشود يجب أن يفقه من يصوغونه "الواقع" الراهن في نظام التعليم المدرسي وأن يلجأوا في تطويره إلى المشاركة الحقيقية للعاملين في هذا "الواقع" سواء في ذلك صياغة أهداف التطوير وتنفيذه. ومشاركة المعلمين فن التطوير مهمة؛ لأفا وسيلة فعالة لحفزهم على تقبل التغيير، والتحمس له، وتقليل مقاومته خفية كانت المقاومة أو ظاهرة.

3.

7 7 
تدل أحدث الكتابات المتعلقة بتحليل الخطاب أن منهج تحليل الخطاب يستخدم -غالباً- في العلوم الاجتماعية لفحص "الرؤى المختلفة للعالم" different versions of the world views لبيان مفرداتها وماهياتها، والعلاقات القائمة بين مكوناتا، وكيفية توظيف هذه الرؤى في حياة الناس، وذلك من خلال تحليل النصوص والأحاديث التي دارت وتدور حول هذه الرؤى.8

واصطلاح الرؤى المختلفة للعالم في الكتابات الغربية مرادف لمصطلح آخر، يستخدم للإشارة إلى نفس المعاني والعمليات، وهو مصطلحParadigm قد تضاربت ترجمات هذا المصطلح إلى اللغة العربية، وأزكي ترجمته إلى " الصيغة الفكرية الحاكمة " اعتمادا على أن أحد معاني الكلمة في المعاجم الإنجليزية هو "صيغة الجذر اللغوي" الذي

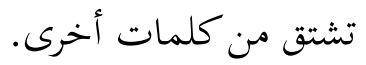

والصيغة الفكرية الحاكمة Paradigm هي التصور العقدي للعالم أو الكون، وللخالق ولطبيعة الإنسان ودوره في الحياة، وللحياة ومسيرةما وصيرورةا. وينشأ عن هذا التصور وتشتق منه تصورات ومفاهيم ومناهج فكرية تتصل: بالعقل، والمعرفة، العلم، ومناهج البحث، وبالنظم والمؤسسات والتنظيمات التي تتفرع عن هذه الصيغة الفكرية الحاكمة.

ولإسلام في جانب العقيدة تصور يختلف عما سبقه من أديان وما تلاه من أيديولوجيات بشرية، وأوجز هذا التصور في كلمات قصيرة لبيان مقتضياته في الخطاب التربوي، دونما مقارنات أو موازنات بين الرؤية الإسلامية وما عداها، فأقول:

• - ل الله، في العقيدة الإسلامية، هو سبحانه خالق الكون بكل ما فيه من ظواهر وأشياء وأحياء، وأنه جل علاه- واحد أحد، لم يلد ولم يولد، وليس له كفء. والربوبية في الإسلام واحدة، لا تعدد فيها ولا مشاركة، وإفراد الله بالعبادة، وبأنه قيوم على من خلق وما خلق، يعني أن يتحرر الناس جميعاً من العبودية لغير الله من بشر - أياً كانوا - أو ظواهر، أو قوى مادية أو فكرية .

8 Silverman, D. Analyzing talk and text. In Denzin, N. \& Lincoln, Y. (Eds). 8 Handbook of Qualitative Research. Thousand Oaks, CA: Sage Publications, 2 ,1994nd edition, P. 896. 
• العالَم في الرؤية الإسلامية عالمان: عالم الغيب المتصل بذات الله وصفاته، والحياة الآخرة، والملائكة والجن والروح. ومصدر العلم بهذا العالم وحي الله إلى أنبيائه ورسله، وخاتمهم رسول الإسلام محمد صلى بلى الله عليه وسلم، ومعجزته القرآن الكريم؛ وعالم الشهادة، ويدخل فيه كل ما في الأرض، وفي الكون من أشياء وأحداث وظواهر، وعلاقات بتري جميعها، وفقاً لسنن الله في الآفاق وفي الأنفس، وهي سنن لا تتبدل ولا تتوقف إلا بقدر الله ومشيئته. • • الإنسان (الجنس) أكرم مخلوقات الله، وتكريمه ماثل في كيانه المتميز عن سائر المخلوقات، بما فطره الله عليه من قابليات وقدرات هيأت له إدراك المؤثرات الكونية، والانفعال بها، والاستجابة لها بكل ما ركب فيه من حواس، وعقل، وطاقات، بتعله قادراً على التفكير والتأمل والتدبر والتوقع، واستشراف المستقبل، والاختيار الحر المسؤول في الفكر وفي العمل، وفي قدرته على تخطي محددات السياق

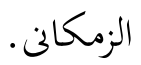

واستناداً إلى تميز الإنسان في تكوينه البدني والعقلي والنفسي فقد استخلفه الله في عمران الأرض، وجعله سيداً

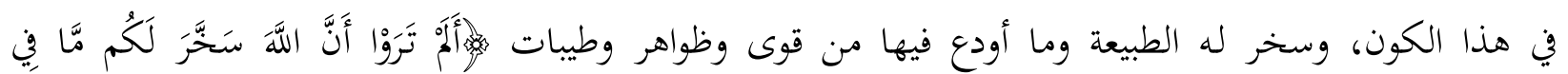

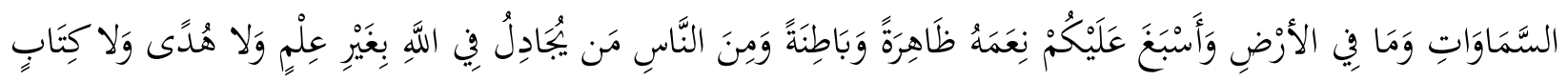

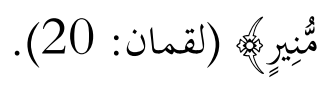

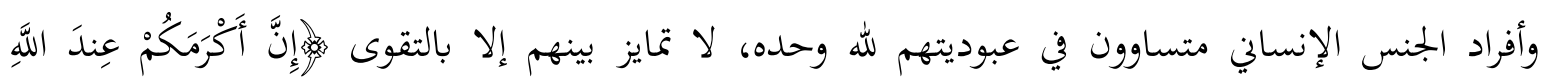

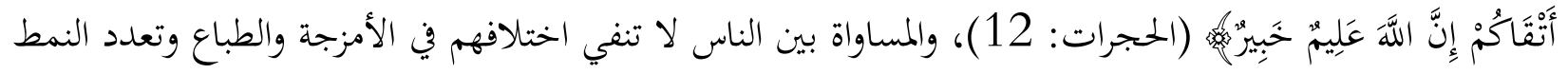

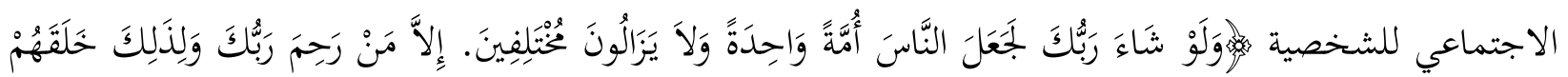

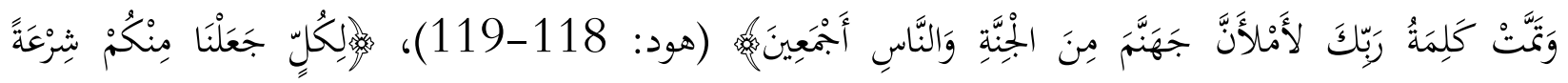
وَمِنْهَاجَا مُهُ (المائدة: 48). وهذا يعني أن الإسلام يقر التنوع الثقافي ويراه وسيلة لإثراء حياة الناس لا لتصارعهم. ويحتل العقل في الصيغة الفكرية الحاكمة في الإسلام مكانة عالية، بوصفه وسيلة الإنسان في الكشف عن أسرار الخالق في الكون، وفي الأنفس -منفردة ومجتمعة- وفي قدرته على الإدراك الحسي، والتصور العقلي، والقيام بعمليات عقلية لاستيعاب المعارف، واختزاها، واستدعائها، وتوظيفها، وتوليد معارف جديدة ومتجددة يستخدمها الإنسان في 
حياته، ويحدث من خلالها تحويلات وتعديلات في مواد الكون وعناصره، وصولاً إلى تنمية حياة البشر وترقيتها، والانتفاع بكل ما في الكون في حدود ما قدر خالق الكون.

وتشهد آيات كثيرة في النتزيل الحكيم بكانة العقل، وحث الناس على إعماله على أنه فريضة إلهية، فهو مناط تكليف البشر بأداء واجباتم واستيفاء حقوقهم. وقد تعددت في القرآن الكريع الآيات الداعية إلى وجوب إعمال العقل بمفردات غختلفة منها النظر، والتدبر، والإتيان بالبرهان، والبينة، والمجادلة بالحسنى، والتببين، والحكمة، والفقه. وقد

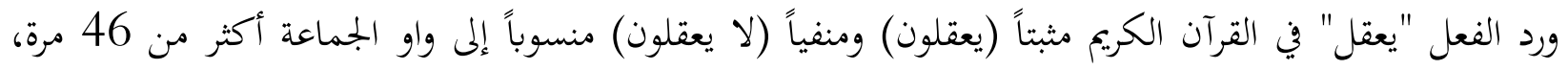
وتلك إشارة إلى ضرورة أن يعمل الفرد عقله، وأن يتم الاعتماد في شئون الأفراد والجماعات، والأمم على العقل الجمعي لأهل الذكر والمعرفة في كل مجال من مجالات الحياة.

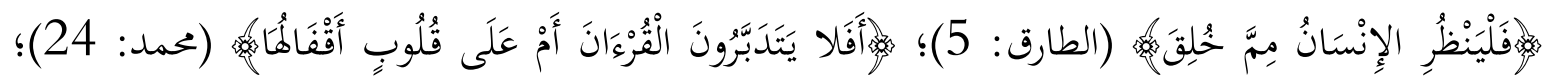

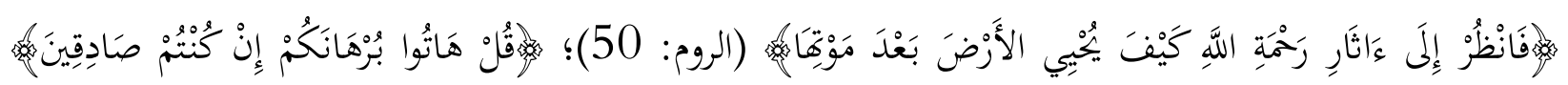
(البقرة: 111)؛

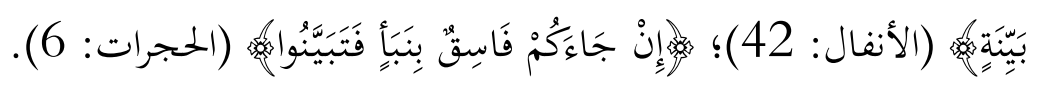

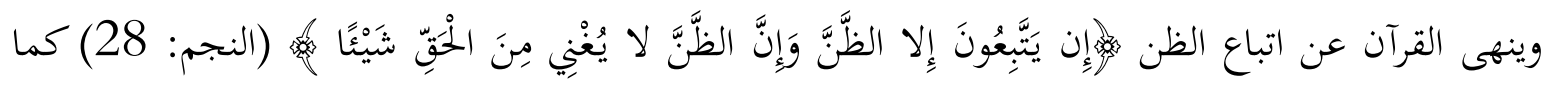

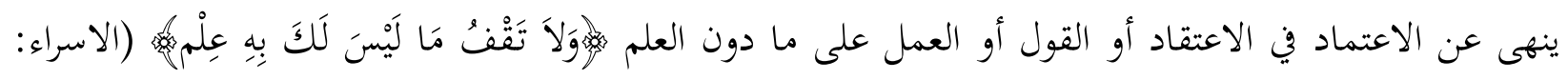

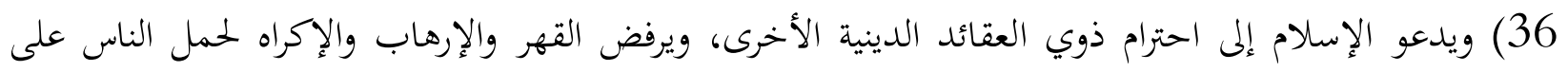

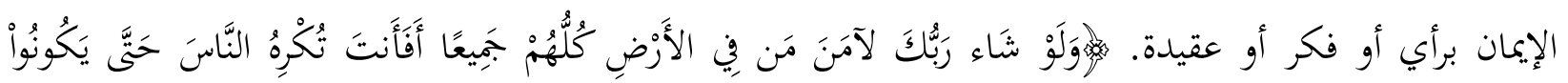

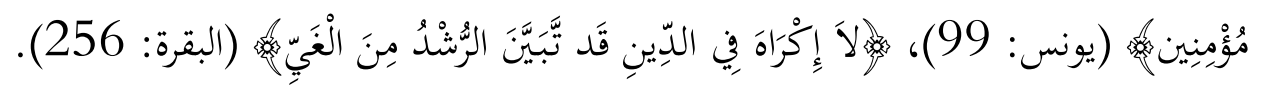

ومفهوم العلم في الإسلام مفهوم يتسم بالشمول، ويعني كل فكر منظم يصل إليه الفكر الإنساني عن

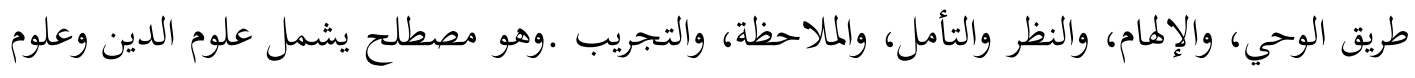

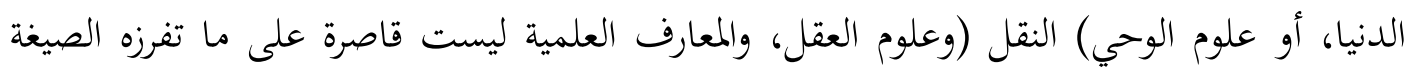
التجريية في العلوم التي توصف بأها منضبطة، وهي العلوم التي توظف فيها، وتولد في جنباةًا معارف الماهيات Know what's أو العلوم التي تتولد من خلالها المعارف النوعية والوسائل التقنية 
Know How’s العلوم والمعارف التي تحدد الغايات والمسارات التي توظف من أجلها، وفيها معارف" الماهيات " و"الكيفيات والتقنيات "ويدخل في هذا النمط الثالث من العلوم ما يتصل" بالصيغ الفكرية الحاكمة " على النحو الذي نمارسه الآن في هذا الجزء من الدراسة، ونعني بها العلوم التي تتصل بالمعتقدات الدينية، والقيم الإنسانية، والفضائل الخلقية .ويعرف هذا الصنف من العلوم والمعارف في الكتابات

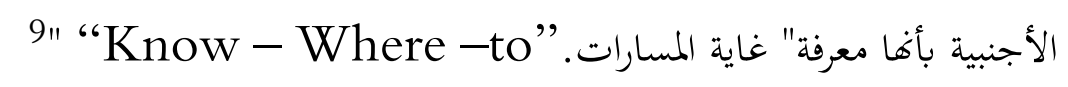

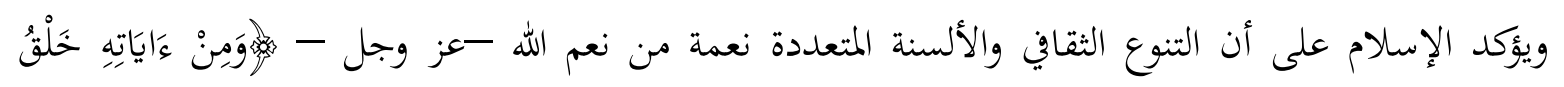

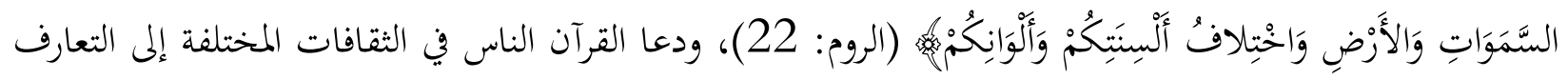
والتعاضد؛ لتأدية الوظائف التي تمكن الإنسان من إعمار الأرض، وأداء أمانة الاستخلاف، والاستمتاع بما أودع الله في

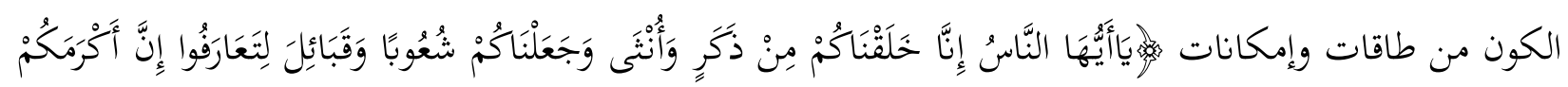

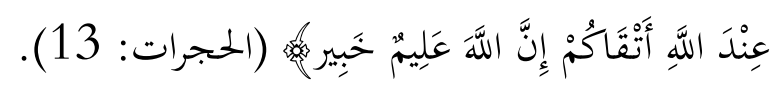

والتبادل الثقافي الذي يدعو إليه الإسلام مشروط في غاياته وموضوعاته وأساليبه بألا يكون تبادلاً أو مشاركة

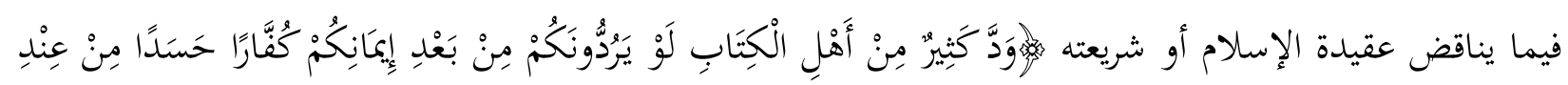

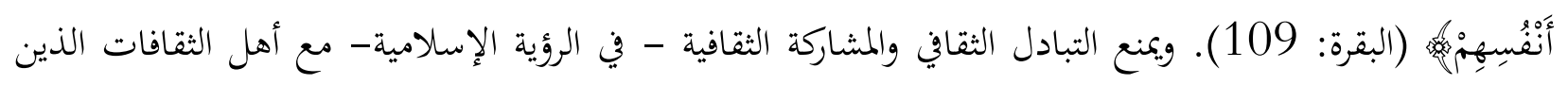
يقاتلون المسلمين، أو يخرجوهم من ديارهم، ومع من يظاهرون الآخرين على قتال المسلمين وإخراجهم من ديارهم.

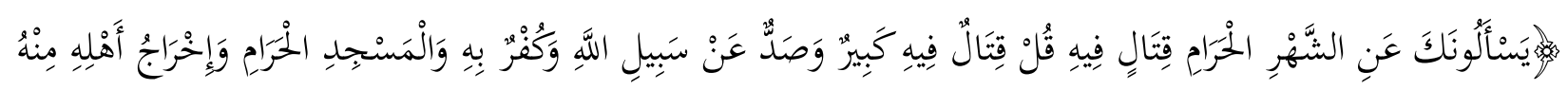

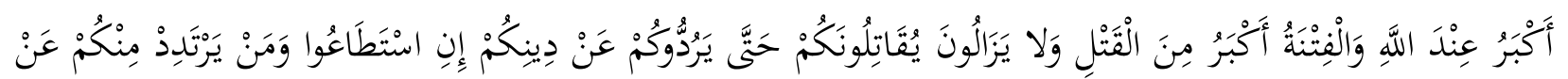

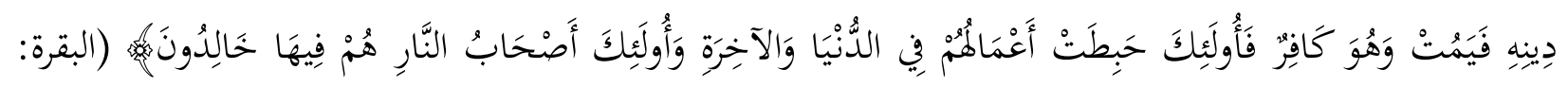

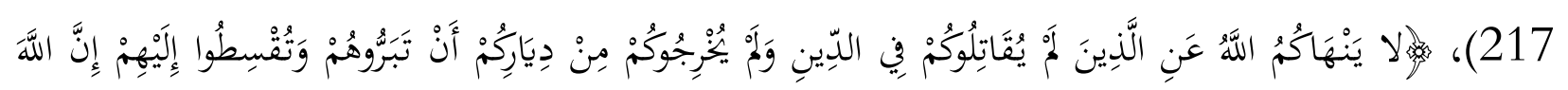

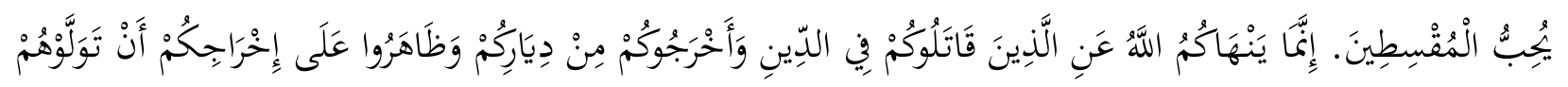

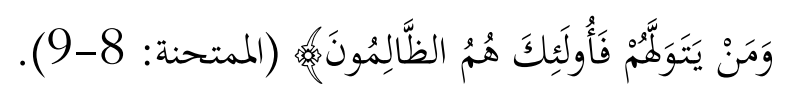

9 - Jantach, E. Design for Evaluation, (1975), New York, N. Y: George Braziller, P.7 
ولا يسمح مقام هذه الدراسة بمزيد من البيان في التصور الإسلامي. وأفي القول في هذا الجزء من الدراسة بتأكيد أن الإسلام يدعو إلى قيم كثيرة تستقيم بها حياة الناس في كل زمان ومكان، منها: تأكيد حرية الإنسان، وإقامة العدل، والتراحم، والإيثار، والصدق في القول وفي العمل. وغهى الإسلام عن الظلم والعدوان، والنفاق، والمراءاة، والفساد، والإفساد، وقول الزور، ونقض العهد، والسرقة، وخيانة الأمانات، والإهمال في أداء الواجبات، وعدم الاضطلاع بمقتضيات المسؤوليات التي يعهد بها إلى الناس. وأنا على يقين أن قراء هذه الدورية قادرون على الكشف ولف عن النصوص القرآنية التي توثق هذه الفضائل الأخلاقية من خلال مراجعة المصادر المعتمدة الخاصة بمعجم ألفاظ القرآن الكريم.

وأحسب أن ما قلناه في تحرير المراد بالخطاب والتربية والإسلام يوحي بالسمات التي تشتق من طبيعة الأبعاد التي يتأسس عليها الخطاب التربوي.

ثانياً: بعض السمات المنشودة في الحطاب التربوي الإسلامي

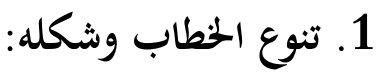

الخطاب التربوي الذي نحن بصدده خطاب يتسم بتنوع من ينشئونه، وتنوع من يتلقونه، كما تختلف الموضوعات التي ينصب عليها الخطاب، مثلما تختلف السياقات التي تكتنفه؛ فالتشريعات والقوانين التي تصدر في شأن مراحل التعليم وأنواعه خطاب تربوي حاكم، وحسن الخطاب في هذه القوانين يستوجب ألا يفاجأ بها المعنيون بالتعليم، يستوي في ذلك الآباء والمعلمون والطلاب وأساتذة التربية في الجامعات. وإنما ينبغي أن تعرض دواعي القانون، ومضامينه، وتضميناته، وتطبيقاته، وتبعاته على كل من يهمهم الأمر بوسائل مختلفة، وبصورة جادة، وليست

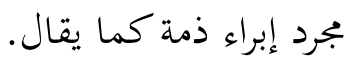

والمواد التعليمية (الكتب المقررة، وأدلة المعلم، وكتب التدريبات، وصحائف العمل التي تعد للطلاب) خطاب تربوي، يجب أن يراعى فيه مقتضى حال من يتلقون هذا الخطاب؛ بمعنى أن يولي المؤلفون اعتباراً كافياً للخلفية المعرفية، 
والبنية الذهنية لمن توجه إليهم هذه المواد، بحيث يستغل في تصميم هذه المواد، وفي تحديد مضامينها، وفي أساليب تحريرها أحدث المعارف المتاحة في مجالها، عربية كانت مصادر هذه المعارف أو أجنبية.

والتواصل بين المعلمين والمتعلمين في المواقف التعليمية خطاب تربوي، وهذا الخطاب يمثل موقفاً مقصوداً

للتواصل، تتم فيه محاورات ومراجعات ومشاورات ذات أثر كبير في النمو العقلي والاجتماعي للمتعلمين. وقد أجريت حوله أبحاث كثيرة، انصب بعضها على "تحليل التفاعل الاجتماعي" بين قطبي التواصل: المعلم والمتعلمون، وانصب بعض آخر على بنيات ومضامين "التفاعل اللفظي."10

ومن أحدث التصورات للخطاب التربوي في الفصول المدرسية أنه موقف للتواصل العقلي، بالمعنى الواسع

للعقل؛ الذي يشمل: الفكر والوجدان والعمل. ويؤكد أهل الثقة في هذا المجال أن ثمة عجزاً مشهوداً في ربط الفكر النظري حول الموقف التعليمي بالممارسات العملية في مواقف التعليم. ويرون: ضرورة إعادة النظر في دور علم نفس النمو في ترشيد الممارسات التعليمية، وأن هذا يتطلب تصورات ذهنية جديدة؛ لا يكفي فيها الإيمان بأن الطفل كائن عاقل مريد؛ بل تتجاوز هذا إلى الإيمان بأن المعرفة البشرية صناعة إنسانية، وبأها منتج ثقافي، يثري المعتقدات المشتركة، ويؤسس أطراً فكرية لفهم العالم الطبيعي والاجتماعي والثقافي الذي يكتنف الفرد والجماعة، وأن المتعلمين في أية مرحلة يمكن أن يشاركوا في صنع المعرفة. وإعادة التفكير على هذا الوجه تصنع أساساً لعلم نفس تربوي حديث، ونماذج جديدة للتفكير ولتعلم وللتدريس تكون مناسبة للقرن الحادي والعشرين. 11

10 من البحوث الرائدة في هذا الججال أعمال (N.A. Flanders) تحت عنوان "تحليل التفاعل الاجتماعي" (Interaction Analysis)

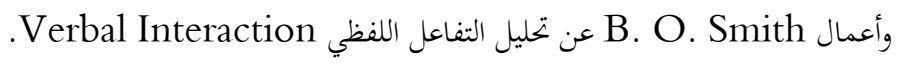
راجع إن شئت

Houston, W.R and Newman, K.K. "Teacher Education Programs" In Encyclopedia of Educational Research (5th Ed) Harald E.Mitzel, editor New York: Macmillan, 1982, PP. 18811893

11 David R Olson and Jerome Bruner "Folk Psychology and Folk Pedagogy" In 11 Olson, D.R and Torrance, N. (Eds) The Handbook of Education and Development, UK: Blackwell Publisber, 1996, ch.2, PP. 9-27 
وقد بسطت القول في هذا الصدد في مكان آخر، 12 وسأعود إليه في هذه الدراسة في مكان تال عند الحديث عن التدريس بوصفه مهنة للتعلم لا للتعليم. وأكتفي هنا بتأكيد أن الخطاب يتنوع تبعاً لاختلاف تصور كل طرف من طرين الخطاب للآخر؛ ولذا فإنه ليس ثمة مشكلة واحدة بتحم أي خطاب تربوي؛ ولكن ثمة بعض القواعد الأساسية المشتركة التي تؤدي إلى نجاح الخطاب التربوي، ومن أبرزها ما يلي:

أن يتوجه الخطاب إلى الحاجات الأساسية التي يحتاج إليها من يوجه الخطاب، بمعنى أن ينصب الخطاب على إشباع حاجات حقيقية لدى المخاطبين، وأن يتلاءم مع اهتماماقم، وأن يكون وسيلة لتوسيع آفاقهم، وزيادة كفاءقم العقلية، وتصعيد فاعليتهم الاجتماعية؛ وهذا هو المراد من تحديد "الحاجات التدريبية "في برامج تدريب المعلمين في أثناء الخدمة (مثلاً).

أن يراعي من يبث الخطاب التربوي المستوى اللغوي للمخاطبين، فليس من الكياسة أن يتحدث معلم باللغة العربية الفصحى لأطفال صغار في السنوات المبكرة من أجل التعليم، فيلجأ إلى غريب الألفاظ أو مهجورها، أو ما يصعب على المتعلمين فهم دلالاته، ولا حرج على المعلم في هذه الحالة أن يلجأ إلى اللغة الفصيحة أو إلى اللهجة العامية، على أن يضع في اعتباره أن هذه حالة مؤقتة، وأن الهدف الذي يجب أن يصل إليه تدريجياً مع الأطفال هو أن تستخدم في الخطاب لغة عربية فصيحة، تكون ملائمة لمستوى المتعلمين في مراحل التعليم المختلفة.

أن يلتزم في صياغة الخطاب بتحقيق معادلة تتردد في التراث العربي" :قدّرِ اللفظ على المعنى، فلا يفضُل عنه، وقدِّر المعنى على اللفظ، فلا ينقص منه ."وخير الخطاب- كما قدمنا ههو ما كان موجزاً إيجازاً غير مخل، ومسهباً إسهاباً غير ممل .وعلى صائغ الخطاب أن يرتبه وفقاً لترتيب تسلسل المعاني، فيقدم الأهم على المهم، ويعرض الكليات قبل الاستغراق في الجزئيات، وأن يستحضر في ذهنه- دائماً -وهو ينسج الخطاب حال المخاطبين؛ فلا يعمد في خطاب غير المتخصصين في موضوع الخطاب إلى إيراد مصطلحات فنية أو تقنية، وضعت لمعان خاصة في العلوم أو أداء الأعمال.

عبد الحليم، أحمد المهدي. نهو مناهج للنماء العقلي. المحاضرة التذكارية، مطبوعات المؤتمر السنوي الثالث عشر لجمعية المناهج المصرية، القاهرة: 12

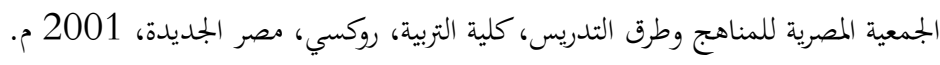


أن يُحَّر في "الخطاب" ما يوحي بأن الكاتب أو المتحدث يسئ الظن بالقارئ أو المستمع؛ لأن الوقوع في مثل هذا العمل من شأنه أن يبرر للمخاطب عزوفه عن التأمل في مضمون الخطاب، والانصراف عنه، ومقاومة ما يدعو إليه، بطريقة شعورية أو لا شعورية، تكون ظاهرة أحياناً وخفية أحياناً أخرى . ومما يلزم تأكيده هنا هو أن" شكل الخطاب لا ينفصل- إطلاقاً -عن مضمونه، وأنه لا يتصورعقلاً -أن يكون ثمة خطاب رشيد يعتمد على" قعقعة "لفظية، أو أن ينجح خطاب في إبلاغ مضمون رفيع المستوي دون أن يعرضه ناسجه في رداء لفظي يعادل مستوى المضمون. وأغي هذه السمة العامة بالتأكيد على أن يُفْْغِ المخاطب وسعه في اختيار المعاني والأفكار والقضايا التي ينصب عليها الخطاب، وأن يتحرى الدقة والضبط والتنقيح في صياغة خطابه شفوياً كان الخطاب أو كتابياً وفي هذا المقام يقول الجاحظ" :وينبغي لمن كتب كتاباً ألا يكتبه إلاعلى أن الناس كلهم له أعداء، وكلهم عالم بالأمور، وكلهم متفرغ له، ... فيتوقف عند فصوله توقف من يكون وزن طمعه في

$$
\text { السلامة أنقص من وزن خوفه من العيب"... }
$$

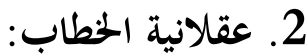

وأبرز ما ينبغي أن يتسم به الخطاب التربوي الإسلامي "العقلانية" والعقلانية الإسلامية عقلانية تختلف عن العقلانية الغربية. التي تحدث عنها فلاسفة اليونان قديماً، كما تختلف عن العقلانية التي قال بها "عمانويل كانت"، والتي كانت إفرازاً ثقافياً أوروبياً، لمواجهة اللاهوت الديني، الذي ساد أوروبا في عصر غضتها، وكلتاهما ترفض الوحي الإلهي، ولا تؤمن إلا بما هو محسوس ومشاهد.

والافتراض الأساسي في العقلانية الإسلامية هو المؤاخاة بين العقل وما جاء به الوحي (النقل) في القرآن الكريم وفي السنة النبوية الثابتة، التي جاءت مبينة ومفصلة لما جاء في القران الكريم، وفي هذا المعنى كانت مقولة ابن رشد: إن النظر البرهاني لا يؤدي إلى مخالفة ما جاء به الشرع للعقل، لأن الحق لا يضاد الحق، بل يوافقه ويشهد له. 14

$$
\begin{aligned}
& 13 \text { 14 الجاحظ، أبو عثمان عمرو بن بحر، كتاب الحيوان، الجزء الأول، تحقيق وشرح عبد السلام محمد هارون. بيروت: دار إحياء التراث الغربي، ص88. }
\end{aligned}
$$

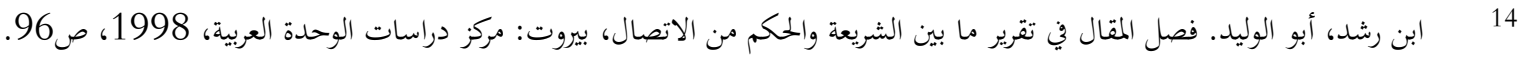


ويرى أحد المفكرين المعاصرين أن مقولة "لا اجتهاد مع النص" تتردد وتعمم -خطأ- في سياقات تنفي الاجتهاد، بمعنى أن يستفرغ أهل الاختصاص جهدهم في فهم النصوص الدينية جميعها، وذلك حيث ينصب الاجتهاد على كل نص ديني يكون "ظني" الثبوت أو "ظني" الدلالة، أو "ظني" الثبوت والدلالة معاً. ويبقى النص الديني "قطعي الثبوت وقطعي الدلالة"؛ وهذا النص لا ينفي إعمال العقل (الاجتهاد) في فهمه، وإنما يستدعي اجتهاداً ذا طبيعة خاصة، جوهرها أن يهتم في الاجتهاد الموجه إلى هذا النص ببيان مدى تحقق العلة الغائية، والمقاصد الشرعية التي توخاها النص في الواقعة أو الوقائع الدنيوية التي يراد إنزال حكم النص قطعي الثبوت وقطعي الدلالة عليها، وذلك

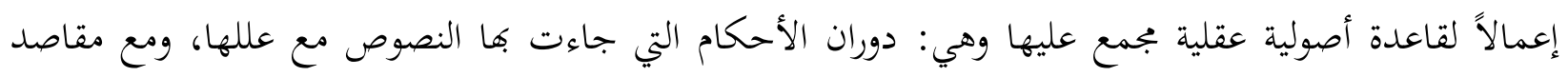
الشرع منها وجودا وعدما، وذلك على نحو ما صنع عمر بن الخطاب رضي الله عنه في وقف إعمال الحكم الذي جاء في نصيب المؤلفة قلوكمم من الصدقات، وفي عدم تطبيق حد السرقة في عام "الرمادة" لعدم تحقق العلة الغائية التي أريدت بالنص في كلتا الحالتين، ووقف إعمال النص لا يعني بطلانه وإنما يعني العودة إليه كلما برزت العلة الغائية المرادة منه.

واستناداً إلى ماهية العقلانية المسلمة -وفي حدود ما قدمنا- فإن الخطاب التربوي المتسم بهذه العقلانية يجب أن يغطي النقاط المفصلية في العملية التربوية النظامية، التي توجز -عادة- في أسئلة محورية مثل ما يلي: * لماذا نُعِلِّمْ والجواب عن هذا السؤال ينصرف إلى تحديد أهداف التعليم المدرسي. وأعتقد أن الصيغة الفكرية التي تحكم مجريات التعليم في البلاد العربية والإسلامية تفرض ألا تتصادم أهداف التعليم في جملتها وفي تفاصيلها مع

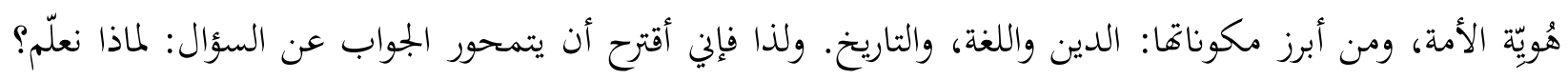
حول: "ترسيخ الأصول الثوابت في الثقافة العربية الإسلامية، وتطوير متغيراتما على نحو يكفل تجديدها، ومواكبتها للتقدم العلمي والتقني المعاصرين، وإقدار الأجيال الناشئة فيها على الإسهام في مسيرة التقدم العلمي والفني على نو لا يفقد المجتمع خصوصياته الثقافية."

* ماذا نعِّمِ؟ والجواب عن هذا السؤال يقع في مجال تحديد المعارف والقيم والاتحاهات والمهارات العملية التي من شأها زيادة الفاعلية للمتعلمين، ورفع كفاءقم الفنية والاجتماعية وتعظيم نزوعهم إلى التعلم مدى الحياة. ويتم

15 عمارة، حمد. في المنهج الإسلامي، الكتاب رقم 4 في سلسلة المنهجية الإسلامية، القاهرة: المعهد العالي للفكر الإسلامي 1991، ص65-73. 
اختيار محتويات التعلم والتعليم في ضوء معايير: الصدق، والحداثة، والقابلية للتعليم، وأن تلائم محتويات التعلم والتعليم احتياجات المجتمع الراهن وحاجاته المستقبلية. على أن تنظم محتويات مناهج التعلم والتعليم في بنيات تتسق مع المعارف المتاحة عن البنية الذهنية للمتعلمين في مراحل تعليمهم المختلفة.

* كيف نُعلّم؟ والمنشود في الخطاب التربوي في البلاد العربية والإسلامية، عند الإجابة عن هذا السؤال أن يعني

هذا الخطاب بتأكيد الأفكار والممارسات التي تم الكشف عنها فيما يخص "التدريس" من حيث النظر إلى أن الغاية المرجوة منه هي "التعلم"، تعلم المعلمين كيف يستثيرون في طلابهم الدافعية للتعلم، وكيف ينجحون في حفزهم للتعلم من خلال جهدهم الذاتي، واستغلال خبراتم ومعارفهم السابقة Metacognition في إثراء كل تعلم جديد يمتاجون إليه.

* كيف نقوّم التعلم؟ والخطاب التربوي في الإجابة عن هذا السؤال مطالب بأن يتحرر من الأنماط التقليدية في تقويم التعلم، وأن يتجاوز الاختبارات والامتحانات التي تقيس القدرة على الحفظ والتذكر، إلى مواقف نختبر فيها مدى تقدم المتعلمين في السيطرة على المهارات العليا للتفكير الناقد من خلال توجهات أساسية مثل: الصياغة الواضحة للمبحث أو القضية التي تعرض للمتعلم، والبحث عن الأسباب التي أدت إلى الوضع الراهن للكيان أو الموضوع أو الظاهرة التي تواجهه، وأن يهتم دائماً بالمواقف الكلية قبل التركيز على الأجزاء، وأن ينظر دائماً في البدائل المحتملة التي يككن أن يتحول إليها الوضع الراهن، وأن يتقبل وجهة النظر المخالفة لوجهة نظره، وأن يؤجل إصدار الأحكام حتى تتوفر لديه أدلة وقرائن كافية تسوغ ما يصدره من أحكام.

ويجب أن يُعنى الخطاب التربوي بتقدير مدى تقدم الطلاب في الاستحواذ على القدرات العقلية التي قيئ لهم معرفة الأسباب المعلنة والأسباب المضمرة فيما يرون أو يسمعون أو يقرؤون أو يعملون، وأن يحددوا أوجه الشبه أو الافتراق فيما يعرض لهم، وأن يتعرفوا على ماله صلة وثيقة بالموقف الذي يعالجونه، وما ليس ذا صلة بهذا الموضوع وأن يكونوا قادرين على تحليل الحجج والبراهين بصورة مختلفة (لغوية-رياضية-بيانية-تشكيلية-موسيقية).

وتقويم التعلم يجب ألا يقتصر على تقدير إنجازات التعلم، وإنما ينبغي أن يتناول التقويم الوسائل التي يتم اتخاذها وسيلة للتعلم: محتويات التعلم، واستراتيجيات التدريس التي أدت إلى نوعية التعلم الذي أحرزه المتعلمون ونخو ذلك. 
ولست في حاجة إلى لفت الانتباه إلى أن الانبغائيات التي تحدثت عنها على أها سمات منشودة في الخطاب التربوي تستدعي تغيراً جذرياً في تصور وظائف الكليات الجامعية القائمة على إعداد المعلم، وفي تصور الوظائف التي يقوم بها تدريب المعلمين في أثناء الحذدة، وإلى التحول من الاختبارات والامتحانات التقليدية إلى نمط جديد يمكن أن يجعل تقويم التعلم مدخلاً إلى تطوير التعليم المدرسي.

وفي محاولة تقويم نظام التعليم المدرسي يجب أن يتبنى الخطاب التربوي المنشود مبدأ ألا يترك هذا التقويم للهيئات الرسمية القائمة فعلاً على تخطيط النظام وتنفيذ إجراءاته؛ إذ ليس من المعقول أن تلتزم هذه الهيئات بالنظر الموضوعي، المبرأ من الأهواء الشخصية في هذا التقويم، وفي مأثوراتا عبارات تتسم بالحكمة، منها أن "صانعة الحبز (وزارات المعارف والتعليم) لا يمكن أن تعيبه"، وأحسب أن تلك غريزة في بني البشر. ولذا فإن تقويم نظام التعليم المدرسي يجب أن يعهد به إلى أجهزة مستقلة تماماً عن الهيئة المركزية الرسمية القائمة على تسيير نظام التعليم، وأن تنتقي لهذه الأجهزة العناصر المؤهلة في مجال تقويم التعلم، واشتهرت بأها لا تخاف سيوف السلطة الحاكمة، وأها -في الوقت ذاته- ليست طامعة في ذهب السلطة، وأها محصنة ضد ما لدى السلطة من غوايات أو إغراءات.

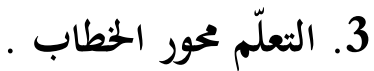

ومن السمات المرجوة في الخطاب التربوي الإسلامي أن يتجلى فيه التحول الجذري الذي حدث في مفهوم الغاية من التعليم المدرسي؛ ذلك أن الربع الأخير من القرن العشرين قد شهد تقدماً ملحوظاً في رؤية مقاصد التعليم المدرسي، واعتمدت هذه الرؤية على براهين متنوعة في طبيعتها في كثير من الأنظمة المعرفية، وثيقة العرى بالتربية مثل: علم نفس النمو، وعلم نفس التعرف Cognitive Psychology وعلم اللغويات، وعلم التواصل، والبحث التربوي ونوها. وقد أعلن هذا التحول في وثيقتين صدرتا عن منظمة يونسكو. كان عنوان أولاهما "تعلم لتكون": وصيغت في هذه الوثيقة الفلسفة التي يمكن الاهتداء بها خلال القرن الحادي والعشرين. وكان جماعها هو مفهوم "التعلم" وليس التعليم أو التدريس، وفيها تم إيضاح أن التدريس ليس غاية في ذاته، وإنما هو وسيلة، غايتها العليا معاونة الآخرين على التعلم، وإن التعلم عملية ذاتية خالصة، وأن التدريس عملية مستقلة عن التعلم، بمعنى أن العلاقة بينهما ليست حتمية؛ إذ يمكن تصور تدريس من مدرس كفء وذى فاعلية، ولكنه لا ينتج تعلماً؛ لعوامل شتى ينتمي معظمها إلى المتعلم ذاته؛ أو إلى متغيرات في سياق الموقف التعليمي. 
وقد صيغت المبادئ الرئيسية التي يجب أن توجه التعلم في القرن الحادي والعشرين في أربعة شعارات أو مبادئ:

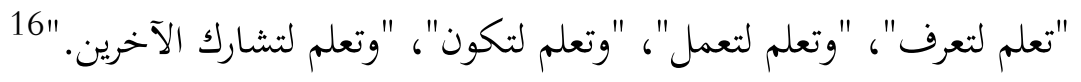

وجاءت الوثيقة الثانية داعمة ومؤكدة للأفكار والمبادئ التي تضمنتها الوثيقة الأولى، وكان عنوان الوثيقة الثانية

هو: التعلم: ذلك الكنز المكنون. 17

وقد سبق صدور هذه الوثيقة، وواكبها، وتلاها مشروعات كثيرة لتطوير التعلم في البلاد المتقدمة، وكان الأساس Teaching as the " الجوهري في هذه المشروعات هو أن ينظر إلى التدريس على أنه "مهنة التعلم

."Learning Profession

وخلاصة ما يقال في هذا الصدد تمثله مقدمة منطقية جداً، قوامها أن تحسين نواتج التعليم المدرسي في أي مجتمع يعتمد أساساً على قوة عمل تنهض بالتدريس. وأن هذه القوة يجب أن تؤهل على مستوى عال، تستوعب من خلاله تعلم طبيعة المعارف والأنشطة التي سوف تتخذ مادة التعلم في مؤسسات التعليم قبل الجامعي، إضافة إلى تعلم المهارات المهنية في مجال التعليم واكتساها، في ضوء ما تذخر به المعرفة المعاصرة في أن الغاية من التدريس هي "معاونة الآخرين على "التعلم"، وليست نقل المعارف من رؤوس المعلمين أو كتبهم إلى رؤوس المتعلمين. وذلك على النحو الذي تتناقل به أرصدة "العملات" في المصارف. وهذا يعني -في عبارة أخرى- أن دور المعلم هو أن يعلِّم المتعلمين كيف يتعلمون؟ وأن يظل هو مدى حياته متعلماً.

ومقتضيات هذه النزعة الجديدة هي ضرورة إعادة النظر جذرياً في بنيات "كليات إعداد المعلم" وتحديث رسالتها، وبحديد برابجها، بما يخدم هذا التحول الجديد؛ ومثل هذه الأعمال مطلوب أيضاً في برامج التدريب في أثناء الحندمة.

16 Edgar, Faure. Learning to be: the World of Education Today and Tomorrow. Paris: UNESCO, 1972.

ونسكو، التعّلم: ذلك الكنز المكنون. تقرير اللجنة الدولية للتربية حول القرن الحادي والعشرين (التربمة العربية)، باريس: يونسكو، 1997

.Unesco. Learning: the within Treasure 
وجدير بالذكر -في هذا الصدد- أن نؤكد أن التعلم لا يقتصر حدوثه على غرفة الصف في المدرسة، وأن الطلاب يتعلمون مما يطلق عليه "المنهج الخفي" أكثر مما يتعلمون من المنهج المقرر المعلن، وأقصد بالمنهج الخففي ما يتشربه الطالب في "التعليم المدرسي" من قيم، ومعتقدات، وأفكار، ومعايير للسلوك والحكم الخلقي ليست معلنة، وإنما يتعلمها الطالب من الإجراءات والتنظيمات والقواعد التي تشكل الأعمال النمطية والعلاقات الاجتماعية التي تحدث داخل النظام التعليمي وداخل المدرسة، وداخل فصول الدراسة، ويكفي هنا ذكر أمثلة توضح مثل هذه القيم والأفكار التي يتشربها الطلاب دون وعي:

* تنويع التعليم إلى تعليم عام يؤهل للجامعة، وتعليم فني يؤهل من يتلقونه للأعمال اليدوية من شأنه أن يرسخ في نفوس المتعلمين الإحساس بدونية من يلتحقون بالتعليم الفني، وعلو المكانة الاجتماعية لمن يلتحقون بالتعليم العام. * تركيز السلطة داخل المدرسة في فرد أو عدد محدود من الأفراد، سواء أكانوا من المعلمين أو الطلاب، يؤكد في نفوس الطلاب الإيمان بفكرة أن القيادة في الأعمال محكومة بالتعيين والاختيار وليست قائمة على المعرفة والخبرة والمشاركة بأسلوب ديمقراطي، يستفاد من خلاله بكل الطاقات والعقليات المتاحة في بجال المدرسة.

* توزيع الطلاب في فصول متمايزة (الفائقين، والعاديين، والضعاف) وفقا للدرجات التي يكصلون عليها في الامتحانات السنوية التقليدية يحفز الطلاب إلى أن يحرزوا درجات عالية بوسائل مختلفة، منها ما هو غير مشروع مثل الغش الفردي والغش الجماعي

* تاون المعلمين في الالتزام بمواعيد أعمالهم، وأداء متطلباتحا على الوجه الأكمل من شأنه أن يؤدى إلى أن يتسيب المتعلمون في أداء واجباتم اقتداء واحتذاء بمعلميهم. * نمط العلاقات السائد في إدارة المدرسة، وفي تواصل المعلمين معها، يمكن أن يوصف بأنه "استبدادي" أو "ديمقراطي" أو "متسيب" ويتعلم الطلاب من خلال متابعتهم لنمط العلاقات السائد في المدرسة أفكاراً وأنماط سلوك تلازمهم في مستقبل حياتم.

* إدراك المتعلمين أن معلميهم تتناقض أفعالم وسلوكياقم مع ما يقولون يرسب في نفوس المتعلمين أنه ليس ضرورياً أن تتطابق الأفعال مع الأقوال، وتلك السمة هي إحدى شائنات الشخصية المسلمة وقد قبحها القرآن الكريم 


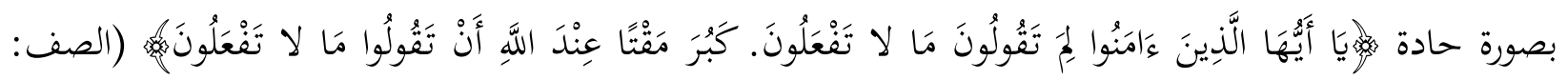

وأفي الحديث عن النظر إلى التدريس على أنه "مهنة التعلم" بتأكد أن هذه السمة المنشودة في الخطاب

الإسلامي تدعمها نتائج بجوث شتى متاحة لمن يريد مراجعتها والإفادة منها. 18

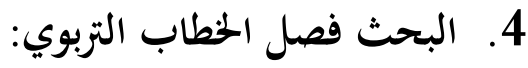

قدمنا - قبلاً - رؤيتنا لطبيعة التعليم المدرسي، ووصفناه بأنه علم أداء أو علم ممارسة، وفصل الخطاب في علوم

الأداء وسيلته البحث العلمي؛ الذي تختبر فيه المقولات والفروض ذات العلاقة بالتربية، والبحث -لغة- التعمق في طلب الشيء، يقال بحث الأرض، وبحث في الأرض بمعنى حفرها، ليعرف ما فيها، وفي التنزيل الحكيم لوفَبَعَثَ اللهّ غُرَابًا يَبْحَثُ فِي الأَزْضِهِِ (المائدة: 31)، وبحث عن الشيء: سأل عنه واستقصاه، ومن الألفاظ العربية وثيقة العرى

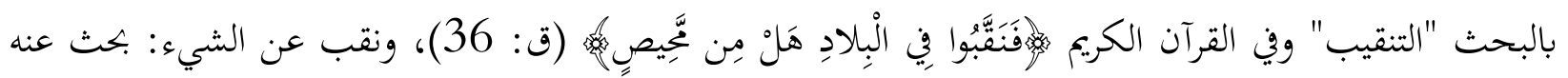
بكثاً بليغاً، والنَّقاب العلامة البحاثة الفطن، ومن الألفاظ ذات الدلالة على البحث أيضاً: "الفحص" من فحص الأرض حفرها، وفحص الشيء كشفه، وفحص الكتاب دقق النظر فيه ليعرف كنها، وتفحص: بالغ في الفحص. 19 وتدل التوطئة اللغوية السابقة على أننا إزاء منظومة من المفردات العربية للتعبير عن البحث هي: البحث، والتنقيب، والاستقصاء، والفحص، وفي اللغة الإنجليزية منظومة مشاهمة هي كلمات: Research; Inquiry; .Investigation; and Induction مشكلات التعليم المدرسي في مستويات مختلفة، ولن أتعرض هنا لهذه المستويات، خشية الخروج عما أريد بهذه

وتدلني ملاحظتي الطويلة للباحثين التربويين، وللبحوث التي يضطلع بها الطلاب للحصول على درجات علمية، وللبحوث التي يقدمها أعضاء هيئات التدريس في كليات التربية للترقية، على أن ثمة التباساً في أذهان الباحثين عن

18 Darling-Hammond, L. and Dykes, G. Teaching as Learning Profession. Handbook of Policy and Practice, San Francisco, CA: Goosey Bass, 1999

$$
\text { يراجع لسان العرب لأبن منظور، والمعجم الوسيط: مرجعان سبق ذكرها. }
$$


طبيعة ما اتفق على تسميته "بحثاً تربوياً" ويتجلى هذا الالتباس أوضح تجليه فيما يقولون عن مشكلة البحث، حيث يجدث خلط كبير بين مشكلة البحث، والغاية منه، ومنهجه، وأدواته، وإزاء هذا فإنني أقدم تصوراً أو تحديداً لما نطلق

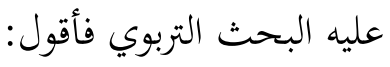

إنه جهد فكرى منظم، تستخدم فيه البيانات والمعلومات والمعارف المتاحة و/أو التي يمكن توليدها عن موقف "مشكل" في إحدى الظواهر التربوية (أهداف التعليم، مناهجه، إداراته، استراتيجيات التعلم والتدريس، تقويم أداء الطلاب، المثغيرات ذات الأثر في المواقف التعليمية، انخفاض العائد من التعلم لدى فرد، أو مجموعة أفراد، أو صف دراسي، أو مرحلة دراسية ونو ذلك)، التي دلت البينات والقرائن المطردة -نسبياً- على أن مخرجات هذا الموقف ليست مكافئة لمدخلاته (الداخلية والخارجية، البشرية والمادية).

والموقف المشكل أو ما نصِفُعُ بأنه "مشكلة البحث" منظومة من العلاقات النشطة -صريحة كانت أو ضمنيةالمتبادلة بين مكونات كيان ما، قد يكون فرداً أو جماعة أو مادة دراسية، أو امتحاناً غائياً، أو طريقة للتدريس، يدل الوضع الراهن على قصور إنتاجه عما هو متوقع في ضوء مكوناته، والإمكانات المتاحة له.

ويستهدف البحث حل المشكلة أو التغلب عليها أو تخفيف حدقّا بصورة كلية تؤثر في الحصيلة النهائية للكيان المبحوث؛ وذلك عن طريق فهم الموقف المشكل في أبعاده كافة: البنيوي والوظيفي والفكري، ووصف واضح للعلاقات والديناميات الفاعلة في الموقف، تفسير الصورة الكلية للموقف المشكل التي أدت إلى عدم تكافؤ مخرجاته مع مدخلاته وعملياته، وأخيراً تطوير "الموقف" ليكون أكثر فاعلية، وأعظم إنتاجاً؛ وذلك من خلال عمليات تشمل إعادة التركيب الهيكلي للموقف، وتحديد مكان المتغيرات ذات الأثر ومكانتها فيه؛ بحيث يسهم كل متغير في أداء دوره متسقاً مع أدوار المتغيرات الأخرى في الموقف، كما تشمل ضبط المدخلات الخارجية للموقف في كمها ونوعها؛ كي تسهم في تحسين المخرجات، إضافة إلى تحسين وأداء المدخلات والعمليات الذاتية الداخلية في الموقف وترشيدها. وأزعم أنّ لمذا التحديد لمفهوم البحث التربوي بعض المزايا، منها تأكيده على الصيغة الكلية للكيان المبحوث في أبعاده كافة؛ سواء في الوصف أو التشخيص أو المعالجة؛ ومنها أيضاً الإشارة إلى المتغيرات والعلاقات الصريحة والضمنية في موقف البحث، وضرورة التعمق في التعرف عليها، وضبط تضميناتما في البحث؛ ومنها كذلك التأكيد أن البحث التربوي ليس غاية في ذاته حسب مقولة: "البحث للبحث"، مضاهاة لمقولة:"العلم للعلم" أو"الفن للفن"، وأن 
غايات البحث تمثل نسيجاً يتكامل فيه: الفهم والاستيعاب، والوصف، والتشخيص، والتدخل أو المعالجة، وتطوير الموقف ليكون أعظم فاعلية، وأكثر إنتاجاً. إن هذا التحديد -فيما أرى- يغطي الصيغ المختلفة للبحث، ويخفف من الاحتراب القائم بينها، وهذه الصيغ التي ينازع بعضها بعضاً في الخطاب التربوي هي: التحليلية الأمبيريقية، والرمزية الثقافية التفسيرية، والصيغة الناقدة. وقد حاولت في أماكن أخرى أن أخلص من تحديدي للبحث التربوي إلى عرض مظاهر الاحتراب بين الصيغ الراهنة فيه إلى البدء في تأصيل ما وسمته بأنه "صيغة إسلامية في البحث التربوي" وأكتفي بالإحالة إلى ما قلت في هذا الصدد. وآمل أن يكون الجها الذي بذلته موضوعاً لحوارات بين المعنيين بالخطاب التربوي الإسلامي.20

\section{خايتة}

أما بعد، فقد أريد هذه الدراسة أن تصف رؤية كاتبها للخصائص المنشودة التي يجب أن يتصف بها الخطاب التربوي الإسلامي المعاصر، وذلك في ضوء فهمه للدلالات المرادة للمفاهيم الثلاثة المفتاحية الواردة في عنوان الدراسة: الخطاب، والتربية، والإسلام، وتحريرها لهذه المفاهيم وعلاقاتما ببعضها.

وقد أكدت الدراسة على ضرورة تطوير الخطاب التربوي الإسلامي، في ضوء عجز مؤسسات التربية في العالم الإسلامي عن الحيلولة دون وقوع الأمة في ما وقعت فيه من ضعف وتخلف، وفي ضوء عجز الخطاب التربوي -الذي قدمته هذه المؤسسات ولا تزال تقدمه- عن الاستجابة للتحديات المستجدة التي تواجه الأمة. وأشارت الدراسة إلى تميّز الإسلام في رؤيته الكلية للكون والإنسان والعلم، وبالتالي تميّه في طبيعة الخطاب التربوي الذي ينشئه من ينطلق في فكره وسلوكه من تلك الرؤية. ثم أوردت الدراسة إشارات موجزة عن بعض السمات والخصائص التي ننشدها في الخطاب التربوي الإسلامي وبخاصة فيما يتعلق بلغة الخطاب ومضمونه، وموقع العقل الإنساني فيه، وموقع المتعلم المخاطب به، وموقع البحث التربوي الذي يفترض أن يقود خطاه.

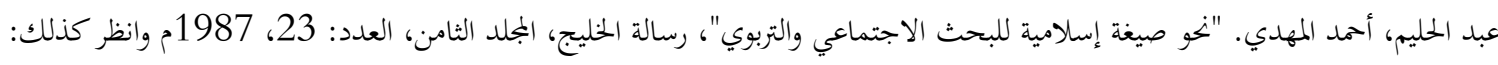

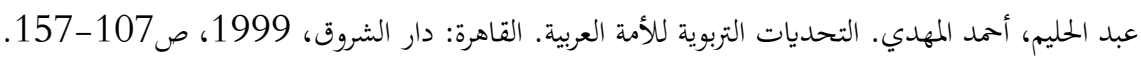


ويجد القارئ فيما قيل عن كل مفهوم منها أنه يتضمن في معناه -على النحو المستخدم في الدراسة- صفات ضمنية للخطاب التربوي. ثم اختتمت الدراسة باختيار عدد من السمات الكلية التي يرى كاتب الدراسة أها سمات أساسية في الخطاب التربوي المنشود في البلاد العربية والإسلامية.

والدراسة على النحو الذي -عُرضت فيه- تمثل نصاً من نصوص "الخطاب التربوي" يتصف بالمراجعة، وبالنظم

الدائري، وليس النظم الرأسي الطولي، وهذا ماثل في عرض الفكرة أو الأفكار في موضع من الدراسة، ثم العودة إليها، وفي هذا الدوران تمثيل للخطاب الذاتي الداخلي الذي كان يختلج في عقل منشئ الدراسة قبل أن يشرع في كتابتها وفى أثناء نظمها. وهذا النص معبأ بمعاني وتصورات وأفكار وأحاسيس، حاول كاتب الدراسة أن يبثها للمعنيين بالتربية في العالم العربي والعالم الإسلامي، وقد أوضحت في ثنايا الدراسة أن الخطاب -أي خطاب- يمثل ألفاظاً خامدة، وبنية سطحية لمقال، ينتظر أن تبعث فيها الحياة بالتعليق، والنقد، والتحاور حول مضمون الخطاب الذي عرض في الدراسة. و الله الموفق والهادي إلى سبيل الرشاد. 